\title{
Culture of human septal chondrocytes in a rotary bioreactor
}

\author{
Marsha S. Reuther, MD¹, Kristen K. Briggs, $\mathrm{PhD}^{2}$, Van W. Wong, BS ${ }^{2}$, Angela A. Chang, \\ MD ${ }^{1}$, Barbara L. Schumacher, BS ${ }^{2}$, Koichi Masuda, MD ${ }^{3}$, Robert L. Sah, MD, ScD ${ }^{2}$, and \\ Deborah Watson, MD, FACS ${ }^{1}$ \\ ${ }^{1}$ Division of Otolaryngology-Head and Neck Surgery, University of California, San Diego, La Jolla, \\ California \\ ${ }^{2}$ Department of Bioengineering, University of California, San Diego, La Jolla, California \\ ${ }^{3}$ Department of Orthopedic Surgery, University of California, San Diego, La Jolla, California
}

\section{Abstract}

1) To show that extracellular matrix deposition is possible in 3-dimensional culture of human septal chondrocytes cultured in a rotary bioreactor as well as in static conditions.

2) To demonstrate that the biomechanical properties of human septal chondrocytes cultured in a bioreactor and static culture amplify with time.

Study Design-Prospective, basic science

Setting-Research laboratory

Methods-Human septal chondrocytes from nine donors were expanded in monolayer and seeded in alginate beads. The beads were cultured in a rotary bioreactor for 21 days in media supplemented with growth factors and human serum, using static culture as the control.

Biochemical and biomechanical properties of the beads were measured.

Results-Glycosaminoglycan (GAG) accumulation significantly increased during two measured time intervals, zero to 10 days and 10 to 21 days $(\mathrm{p}<0.01)$. No significant difference was seen between the static and bioreactor conditions. However, substantial type II collagen production was demonstrated in the beads terminated at day 21 of culture in both conditions. In addition, the biomechanical properties of the beads were enhanced at 21 days in comparison to beads from days 0 and 10.

Conclusion-Human septal chondrocytes cultured in alginate beads exhibit significant matrix deposition and improved biomechanical properties after 21 days. Enhanced matrix deposition during bead culture will expectantly lead to formation of neocartilage that is comparable to native tissue. Matrix production in beads is supported by the use of a rotary bioreactor.

Corresponding Author: Marsha Reuther University of California, San Diego Division of Otolaryngology-Head and Neck Surgery 3350 La Jolla Village Drive, 112-C San Diego, CA 92161, USA mreuther@ ucsd.edu Phone: (858) 642-3405 Fax: (858) 552-7466. 


\section{Introduction}

The repair of cartilaginous defects created by trauma, tumor resection, and congenital deformities requires analogous reconstructive material to obtain optimal results.

Components used for grafting include autologous, allogenic, and synthetic structures. The use of synthetic grafts may be complicated by infection and extrusion, while allogenic grafts carry the risk of immune rejection and disease transmission. ${ }^{1-4}$ Therefore, autologous grafts are favored. Potential autologous cartilage donor sites include the nasal septum, auricle, and rib. Nasal septal cartilage offers significant advantages over these other cartilage donor sites due to its superior structural properties, ease of harvest, and minimal donor site morbidity. However, the use of nasal septal cartilage is limited by the finite amount of tissue available and potentially suboptimal geometric structure for repair of some defects. Tissue engineering of autologous neocartilage, therefore, offers the potential to produce large quantities of autologous cartilage from a small donor specimen and affords the ability to create grafts in defined shapes and sizes.

Nasal septal cartilage engineering involves several key steps. Cartilage is harvested from a donor and chrondrocytes are isolated by digesting the extracellular matrix (ECM).

Chrondrocytes are then proliferated in monolayer culture which causes the chrondrocytes to undergo a shift toward a fibroblastic phenotype in a process called dedifferentiation. ${ }^{5-6}$ The cells are then cultured in a three-dimensional (3D) configuration which induces redifferentiation to the chondrocyte phenotype with production of functional cartilaginous ECM. ${ }^{7-9}$ The redifferentiated cells are then incubated to form neocartilage constructs which can eventually be used for clinical application. Multiple factors influence chondrocyte redifferentiation, including media composition, growth factors, cell seeding density, 3D scaffold properties, and physical stimulation. In turn these factors affect the ability of chondrocytes to produce functional cartilaginous matrix and thereby form clinically useful cartilage constructs.

Mechanical stimulation has been shown to favorably influence cartilage formation and, therefore, is an important factor to take into account during the development of tissue engineered cartilage. ${ }^{10}$ To address this issue, bioreactors have been created that allow for the control of mechanical stimuli and fluid flow. Studies using tissue engineered articular cartilage have demonstrated improved histologic and biochemical properties after culture in a bioreactor (BR) compared with static conditions. ${ }^{11-14}$

The application of BRs to septal tissue engineering has been limited. Moreover, the development of tissue engineered nasal septal constructs that possess the biomechanical and biological properties of native tissue has not yet been achieved. The goal of this study was to determine if 3D culture of human nasal septal chondrocytes in a rotary BR improves histologic, biochemical, and biomechanical properties when compared with static culture. 


\section{Methods}

\section{Cartilage Digestion and Chondrocyte Isolation}

Human septal specimens removed during routine surgery at the University of California, San Diego Medical Center or San Diego Veterans Affairs Medical Center (prior IRB approval), which would have otherwise been discarded, were used. Within 48 hours of procurement, each cartilage specimen was dissected free of perichondrium and diced into pieces $\left(1 \mathrm{~mm}^{3}\right)$. The fragments were digested by incubation at $37^{\circ} \mathrm{C}$ in $0.2 \%$ Pronase type XIV (Sigma, P-5417) in medium (DMEM [Dulbecco's Modified Eagle Medium; HyClone]/F-12, 2\% HS, $0.4 \mathrm{mmol} / \mathrm{L}$ l-proline, $2 \mathrm{mmol} / \mathrm{L}$ l-glutamine, $0.1 \mathrm{mmol} / \mathrm{L}$ nonessential amino acids, 10 $\mathrm{mmol} / \mathrm{L}$ HEPES buffer, $100 \mathrm{U} / \mathrm{mL}$ penicillin $\mathrm{G}, 100 \mu \mathrm{g} / \mathrm{mL}$ streptomycin sulfate, 0.25 $\mu \mathrm{g} / \mathrm{mL}$ amphotericin B) for 60 minutes followed by incubation with $0.025 \%$ collagenase $P$ (Roche Diagnostics, \#1249-002) in medium for 12 to 15 hours. Suspensions of digested cartilage were filtered $(70 \mu \mathrm{m})$, then washed and centrifuged. Cells were resuspended in cell culture medium (DMEM [low glucose], $2 \% \mathrm{HS}, 25 \mu \mathrm{g} / \mathrm{mL}$ ascorbate, $0.4 \mathrm{mmol} / \mathrm{L}$ 1-proline, $2 \mathrm{mmol} / \mathrm{L} \mathrm{l-glutamine}, 0.1 \mathrm{mmol} / \mathrm{L}$ nonessential amino acids, $10 \mathrm{mmol} / \mathrm{L}$ HEPES buffer, $100 \mathrm{U} / \mathrm{mL}$ penicillin $\mathrm{G}, 100 \mu \mathrm{g} / \mathrm{mL}$ streptomycin sulfate, $0.25 \mu \mathrm{g} / \mathrm{mL}$ amphotericin B). The number of chondrocytes was determined by hemacytometer counting after trypan blue exclusion.

\section{Expansion in Monolayer}

For each patient, isolated chondrocytes were seeded at low density $\left(5,000\right.$ cells per $\mathrm{cm}^{2}$ surface area) into T-175 flasks. Monolayer cultures were incubated in a humidified atmosphere at $37^{\circ} \mathrm{C}$ with $5 \%$ carbon dioxide/air. Culture medium was supplemented with $2 \%$ pooled human AB serum (Gemini Bioproducts, Woodland, CA), 1ng/mL TGF $\beta-1$, $5 \mathrm{ng} / \mathrm{mL}$ FGF-2, and 10ng/mL PDGF-bb, and changed every two days. Chondrocytes were grown until confluency (7-10 days).

\section{Culture in Alginate}

The expanded cells were released from monolayer using 0.05\% trypsin (Life Technologies, \#25095-019) for ten minutes at $37^{\circ} \mathrm{C}$. Enzyme action was terminated with cold media. After serial centrifugation and aspiration of the supernatant, chondrocytes were counted using a hemacytometer. These cells were suspended at a density of $4 \times 10^{6}$ cells $/ \mathrm{mL}$ in a solution of $1.2 \%$ alginate in $0.15 \mathrm{M} \mathrm{NaCl}$. Droplets of the alginate/chondrocyte solution were polymerized in $102 \mathrm{mM} \mathrm{CaCl}_{2}$ to form beads. The volume of each bead was approximately $10 \mathrm{~mm}^{3}$ (40,000 cells). After washing with $0.9 \%$ saline, 100 beads were transferred to a 250 $\mathrm{mL}$ Nalgene PETG square media bottle and 100 beads were transferred into a $50 \mathrm{~mL}$ disposable rotary cell culture vessel (Sythecon, Inc., Houston, TX). Fifty milliliters of alginate culture medium (DMEM/F-12, $25 \mu \mathrm{g} / \mathrm{mL}$ ascorbate, $0.4 \mathrm{mM}$ L-proline, $2 \mathrm{mM} \mathrm{L-}$ glutamine, $0.1 \mathrm{mM}$ nonessential amino acids, $10 \mathrm{mM} \mathrm{L}$ HEPES buffer, $100 \mathrm{U} / \mathrm{mL}$ penicillin $\mathrm{G}, 100 \mu \mathrm{g} / \mathrm{mL}$ streptomycin sulfate, $0.25 \mu \mathrm{g} / \mathrm{mL}$ amphotericin B) supplemented with $2 \% \mathrm{HS}$, $100 \mathrm{ng} / \mathrm{ml} \mathrm{BMP-14}$, and 200ng/ml IGF-1 were placed in the media bottle and rotary culture vessel and changed every 2-3 days. Day zero beads were set aside for each patient and testing for histologic, biochemical, and biomechanical properties. 


\section{Release from Alginate Culture}

Culture of alginate beads was terminated at 10 and 21 days. Alginate beads were either subjected to mechanical testing or were depolymerized using a solution of $55 \mathrm{mM}$ sodium citrate and $0.15 \mathrm{mM} \mathrm{NaCl}$. Centrifugation at $750 \mathrm{~g}$ for five minutes was then undertaken to separate the supernatant from the pellet consisting of recovered chondrocytes and cell associated matrix (CAM). The pellets being used for the biochemical assays were digested either with Proteinase K (PK) in phosphate-buffered EDTA or pepsin, overnight

\section{Quantitative Assay for Cellularity}

Cellularity of the terminated and day zero cultures was tested using the PicoGreen DNA content determination assay. The fluorescence of mixtures of $100 \mu \mathrm{l}$ digested samples with $100 \mu \mathrm{l}$ PicoGreen dsDNA quantitative reagent was measured with an excitation light wavelength of $480 \mathrm{~nm}$ and emission wavelength of $520 \mathrm{~nm}$ in a spectrofluorimetric plate reader, and was determined in duplicate. Fluorescence values were converted to DNA quantity using standards of human DNA in the appropriate buffer solution. ${ }^{15}$

\section{Quantitative Assay for GAG}

The GAG content in the PK digests was determined using the dimethylmethylene blue (DMMB) assay. Forty $\mu \mathrm{L}$ aliquots of digested samples were added to $360 \mu \mathrm{L}$ portions of DMMB dye. Absorbance values were determined at $525 \mathrm{~nm}$ in a spectrophotometric plate reader and compared to a plot of standards made from shark chondroitin sulfate type $\mathrm{C}$ (Sigma, St. Louis, MO). GAG content was then be normalized per bead and to DNA content. ${ }^{16}$

\section{Quantitative Assays for Type I and II Collagen}

The amount of type I and type II collagen in the PK digests was quantified by enzymelinked immunosorbent assay (ELISA) using human type I and native type II collagen kits (Chrondrex Inc, Redmond, WA). ${ }^{17}$ Collagen was digested with $10 \mathrm{mg} / \mathrm{mL}$ pepsin dissolved in $0.05 \mathrm{M}$ acetic acid at $4^{\circ} \mathrm{C}$ overnight, followed by incubation with $1 \mathrm{mg} / \mathrm{mL}$ pancreatic elastase at $4^{\circ} \mathrm{C}$ for 16 hours. Separate type I and type II collagen ELISAs were performed following the manufacturer's instructions. Samples and the provided standards were diluted with buffer form the kit. Capture antibodies were added and incubated at room temperature for 2 hours. After washing, the samples were incubated with streptavidin peroxidase for 1 hour. After rinsing, the color reaction was initiated by adding o-phenylenediamine and urea$\mathrm{H}_{2} \mathrm{O}_{2}$. The reaction was terminated by adding $2 \mathrm{~N}$ sulfuric acid. The optical density was read at 490nm with an Emax precision microplate reader (Molecular Devices, Sunnyvale, CA). Collagen values were then normalized to DNA content.

\section{Histology}

Beads were analyzed by histochemistry to localize GAG and by H\&E staining. After depolymerization of the alginate beads, the cells were pelleted, rinsed, and resuspended in PBS. They were placed on poly-L lysine coated slides (Polysciences Inc., Warrington, PA) and allowed to dry overnight. For staining with $\mathrm{H} \& \mathrm{E}$, slides from each sample group were stained sequentially in $0.6 \%(\mathrm{w} / \mathrm{v})$ Hematoxylin in a solution containing $0.06 \%(\mathrm{w} / \mathrm{v})$ 
sodium iodate, $5.28 \%(\mathrm{w} / \mathrm{v})$ aluminum sulfate hydrate, $25 \%(\mathrm{v} / \mathrm{v})$ ethylene glycol, and $6 \%$ (v/v) glacial acetic acid in water (StatLab Medical Products, Mckinney, TX), Scott's Bluing Reagent (StatLab Medical Products, McKinney, TX), followed by $0.025 \%$ (w/v) Eosin Y in a solution containing 54\% (v/v) denatured alcohol composed of 5 parts methanol, 3.6\% (v/v) isopropanol, $1 \%(\mathrm{v} / \mathrm{v})$ methyl isobutyl ketone, and $1 \%(\mathrm{v} / \mathrm{v})$ glacial acetic acid in water (StatLab Medical Products, McKinney, TX) with rinses in water between each stain solution. For histochemical localization of GAG, slides from each sample group were stained with $0.1 \%$ alcian blue in buffer $\left(0.4 \mathrm{M} \mathrm{MgCl}_{2}, 0.025 \mathrm{M}\right.$ NaAcetate, $2.5 \%$ glutaraldehyde, $\mathrm{pH}$ 5.6) overnight, and destained with $3 \%$ acetic acid until clear. ${ }^{18}$ Samples were then observed using light microscopy.

\section{Immunohistochemistry}

Immunohistochemistry was performed with the Vectastain Elite ABC kit (Vector Laboratories, Burlingame, CA), a peroxidase-based detection system. The slides were prepared as described above. After rinsing in $\mathrm{ABC}$ buffer, the samples were blocked with $2.5 \%$ normal horse for 20 minutes. The samples were then probed with one of three antibodies: anti-collagen type I (Sigma) at a dilution of 1:2000, anti-collagen type II (Chrondrex Inc, Redmond, WA) at a dilution of 1:10000, or a mouse nonspecific IgG used at $1 \mathrm{ug} / \mathrm{mL}$ as a negative control. Sections were counterstained with methyl green nuclear stain (Vector Laboratories, Burlingame, CA). Samples were then documented by photomicroscopy.

\section{Biomechanical Testing}

Alginate beads at day zero and day 21 of culture were collected for each sample and condition. The thickness of each bead was measured twice using a contact-sensing micrometer. Alginate beads were transferred to an unconfined test chamber filled with PBS with calcium and magnesium solution at $22^{\circ} \mathrm{C}$ and attached to a mechanical spectrometer (DynaStat, IMASS, Accord, MA). Automated electromechanical testing and data acquisition were implemented by interfacing a computer-controlled function generator (HP33120A, Hewlett-Packard, Palo Alto, CA) to the mechanical spectrometer, and the load and displacement signals from the spectrometer as well as the streaming potential signal from the amplier to a multi-function 16 bit I/O board (NB-MIO-16XH-42, National Instruments, Austin, TX). The test sequence consisted of applying 0-5\% ramp compression over 60 seconds to the sample and allowing the resultant load to relax to equilibrium for 300 seconds. This was followed by application of a series of oscillatory displacements decreasing in amplitude (relative to the compressed thickness) from $3 \%$ at frequencies of $0.01,0.1$, and $1 \mathrm{~Hz}$ while the load was measured. The sample was then subjected to additional ramp compressions to $10 \%, 15 \%$ and then $20 \%$, and oscillatory tests at the same amplitudes and frequencies were conducted at each static offset compression level.

The compressive properties of the alginate bead samples were estimated from the acquired data assuming tissue homogeneity. The material stiffness, E, was determined as a linear estimation to fit the equilibrium stress-strain data $(0,5,10,15$, and $20 \%)$. 


\section{Statistical Analysis}

Analysis was performed using Systat 10.2 (Systat Software, Chicago, IL). Means are presented \pm the standard deviation (SD). Differences in DNA content per bead, GAG per bead and GAG per DNA, collagen, and confined compression modulus were assessed using repeated measures analysis of variance (ANOVA) with two within subject factors, condition and time, to determine the fixed effect of condition and time. If the ANOVA identified an overall significant effect, post-hoc Tukey's HSD tests were used to identify significant differences between time points. A paired t-test was used to analyze the difference in type II collagen content between the static and BR conditions. A difference was considered significant when $\mathrm{p} \unlhd 0.05$.

\section{Results}

Alginate beads gradually increased in size from day zero until termination of culture at day 21. Biochemical testing demonstrated no difference in DNA content per alginate bead between the static and BR conditions ( $p=0.476$; data not shown). Additionally, an initial decrease in DNA content per alginate bead from day 0 to day 10 of culture was demonstrated with $0.861 \pm 0.477 \mu \mathrm{g}$ DNA per bead at day zero, $0.606 \pm 0.275 \mu \mathrm{g}$ DNA per bead at day 10 in static culture, and $0.573 \pm 0.362 \mu \mathrm{g}$ DNA per bead at day 10 in the BR. There was a significant increase in proliferation reflected by DNA content per bead from day 10 to day 21 of culture $(0.747 \pm 0.170 \mu \mathrm{g}$ DNA per bead in static culture and $0.890 \pm$ $0.402 \mu \mathrm{g}$ DNA per bead in the BR; $\mathrm{p}<0.01)$. GAG accumulation, calculated as $\mu \mathrm{g}$ GAG per $\mu \mathrm{g}$ DNA, did not differ significantly between static culture and the BR $(\mathrm{p}=0.509)$.

However, a significant increase in GAG content was observed during the two measured time intervals, day 0 to 10 and 10 to 21 ( $p<0.001$; Figure 1). GAG content at day 0 was $1.47 \pm$ $3.52 \mu \mathrm{g}$ GAG per $\mu \mathrm{g}$ DNA which increased to $11.00 \pm 3.81 \mu \mathrm{g}$ GAG per $\mu \mathrm{g}$ DNA at day 10 in static culture and $12.94 \pm 6.14 \mu \mathrm{g}$ GAG per $\mu \mathrm{g}$ DNA at day 10 in the BR. GAG accumulation further increased to $49.24 \pm 11.81 \mu \mathrm{g}$ GAG per $\mu \mathrm{g}$ DNA at day 21 in static culture and $49.99 \pm 15.75 \mu \mathrm{g}$ GAG per $\mu \mathrm{g}$ DNA at day 21 in the BR. Type II collagen content in day zero beads was below the limit of detection for the assay. The day 21 beads showed a robust accumulation of type II collagen, but this did not significantly differ between the static and BR culture conditions $(0.512 \pm 0.332$ and $0.417 \pm 0.523 \mu \mathrm{g}$ type II collagen per $\mu \mathrm{g}$ DNA, respectively; $\mathrm{p}=0.639$; Figure 2 ). Type I collagen content was below the limit of detection for the assay $(0.08 \mu \mathrm{g} / \mathrm{mL})$ in day 0 and day 21 beads for both conditions (data not shown).

Histologic examination of the alginate beads confirmed the biochemical findings above. H\&E staining of the alginate beads demonstrated increasing amounts of ECM surrounding each cell with increasing culture time. Alcian Blue staining demonstrated robust staining in day 21 beads, indicating the presence of sulfated GAGs (Figure 3). Immunohistochemical staining confirmed the absence of type I collagen in the alginate beads. Both day 10 and 21 beads demonstrated strong staining for type II collagen, however (Figure 4). Overall, staining did not differ between the static and BR culture conditions.

Biomechanical testing showed....Figure 4? 


\section{Discussion}

Human septal chondrocytes cultured in alginate beads exhibit significant GAG and type II collagen accumulation after 21 days of culture in both static and bioreactor conditions. This increase in collagen and matrix deposition is reflected in the enhanced compressive properties of 21 day beads.

Bioreactor systems provide mechanical stimulation during cell culture. This has been shown to favorably influence cartilage formation in vivo. ${ }^{10}$ The chondrogenic effect of bioreactors on cultured articular chondrocytes has been well established. Sheehy and colleagues ${ }^{14}$ studied the effect of dynamic rotational culture on porcine chondrocyte constructs. They found that rotation significantly increased GAG and collagen production in constructs compared with static culture. Freed and colleagues ${ }^{19}$ seeded bovine articular chondrocytes onto biodegradable polymer scaffolds and cultured them in a rotating bioreactor for 40 days. The resultant constructs exhibited accumulation of GAG and type II collagen, suggesting the promising effect of rotating bioreactors on chondrogenesis. Similarly, Vunjak-Novakovic and colleagues ${ }^{20}$ cultured bovine articular chondrocytes for 6 weeks on fibrous polyglycolic acid scaffolds in static flasks, mixed flasks, and rotating vessels. They found that static culture and mixed flasks produced constructs with poor mechanical properties. However, the constructs cultured in rotating vessels exhibited robust ECM with the highest percentage of GAG and collagen, in addition to superior mechanical properties. Pound and colleagues ${ }^{21}$ cultured human articular chondrocytes encapsulated in alginate/chitosan microcapsules. The chondrocytes were cultured in a rotating bioreactor, perfused bioreactor, and static conditions for 28 days. Chondrocytes cultured in the rotating bioreactor showed histology similar to native cartilage, while those cultured in the other conditions were less organized. In addition, chondrocytes cultured in the rotating bioreactor demonstrated increased DNA and protein content compared with perfused or static culture. These studies suggest that the use of bioreactor systems for the culture of articular cartilage constructs may promote chondrogenesis and enhance tissue maturation.

The application of bioreactors in nasal septal tissue engineering has been limited. Gorti and colleagues $^{22}$ observed a more mechanically robust construct with handling when human septal chondrocytes were cultured in a slowly turning lateral vessel bioreactor for 6 weeks compared to constructs cultured in a spinner flask for 14 days; however, no tests were performed to confirm the biomechanical integrity. Rotter and colleagues ${ }^{23}$ cultured constructs on resorbable polymer fleece in a perfusion culture vessel for up to 14 days. They reported that all the constructs maintained their original size and shape after 10 days in perfusion culture and the integrity of the polymer scaffolds was maintained. Histological evaluation of the constructs confirmed the presence of ECM and collagen; however, no quantitative measurements were obtained. More recently, Bichara and colleagues ${ }^{24}$ seeded human septal chondrocytes onto non-degradable porous Poly(vinyl alcohol) (PVA) hydrogel to create biosynthetic constructs. These were either directly implanted into nude mice or first cultured in a spinner flask bioreactor system for 10 days and then implanted into the mice. The constructs were then compared after 6 weeks of in vivo implantation. They found that the constructs initially cultured in the bioreactor had higher levels of DNA, GAG, and hydroxyproline (a measure of collagen). In addition, these constructs showed a $22 \%$ increase 
in compressive strength. Overall, the use of bioreactors in tissue engineered articular and septal cartilage has been promising However, prior to this study, the application of a rotating bioreactor for the culture of human nasal septal chondrocytes embedded in alginate has not been performed.

Although the results of this study are encouraging, additional work is needed to ultimately produce clinically useful cartilage constructs. While we show that culture in a rotating bioreactor produces comparable ECM and type II collagen production in alginate beads, no significant difference exists between the two culture systems. However, this study specifically focused on the alginate bead stage of culture and did not examine the effects of bioreactor culture at the construct stage. Prior studies using articular chondrocytes focused on bioreactor culture of constructs. ${ }^{14,19-20}$ The evaluation of the effect of bioreactor culture on nasal septal construct maturation is planned for the future.

In this study, we successfully showed that human septal chondrocytes cultured in alginate beads exhibit significant matrix deposition and improved biomechanical properties after 21 days. Enhanced matrix deposition during bead culture will expectantly lead to formation of neocartilage that is comparable to native tissue. Additionally, ECM and type II collagen production in alginate beads is supported by the use of a rotary bioreactor.

\section{Acknowledgments}

This project was supported by the American Academy of Otolaryngology - Head and Neck Surgery Foundation Resident Research Award (A.A.C.), a Veterans Administration Merit Grant (D.W.), and NIH R01 AR044058 (R.L.S.).

\section{References}

1. Tardy ME Jr. Denneny J 3rd, Fritsch MH. The versatile cartilage autograft in reconstruction of the nose and face. Laryngoscope. May; 1985 95(5):523-533. [PubMed: 3990484]

2. Komender J, Marczynski W, Tylman D, Malczewska H, Komender A, Sladowski D. Preserved tissue allografts in reconstructive surgery. Cell Tissue Bank. 2001; 2(2):103-112. [PubMed: 15256921]

3. Collawn SS, Fix RJ, Moore JR, Vasconez LO. Nasal cartilage grafts: more than a decade of experience. Plast Reconstr Surg. Nov; 1997 100(6):1547-1552. [PubMed: 9385970]

4. Romo T 3rd, McLaughlin LA, Levine JM, Sclafani AP. Nasal implants: autogenous, semisynthetic, and synthetic. Facial Plast Surg Clin North Am. May; 2002 10(2):155-166. [PubMed: 15062318]

5. von der Mark K, Gauss V, von der Mark H, Muller P. Relationship between cell shape and type of collagen synthesized as chondrocytes lose their cartilage phenotype in culture. Nature. Jun; 1977 9(5611):267, 531-532.

6. Homicz MR, Schumacher BL, Sah RL, Watson D. Effects of serial expansion of septal chondrocytes on tissue-engineered neocartilage composition. Otolaryngol Head Neck Surg. Nov; 2002 127(5):398-408. [PubMed: 12447233]

7. Benya PD, Shaffer JD. Dedifferentiated chondrocytes reexpress the differentiated collagen phenotype when cultured in agarose gels. Cell. Aug; 1982 30(1):215-224. [PubMed: 7127471]

8. Homicz MR, Chia SH, Schumacher BL, Masuda K, Thonar EJ, Sah RL, Watson D. Human septal chondrocyte redifferentiation in alginate, polyglycolic acid scaffold, and monolayer culture. Laryngoscope. Jan; 2003 113(1):25-32. [PubMed: 12514377]

9. Chia SH, Homicz MR, Schumacher BL, Thonar EJ, Masuda K, Sah RL, Watson D. Characterization of human nasal septal chondrocytes cultured in alginate. J Am Coll Surg. May; 2005 200(5):691704. [PubMed: 15848359] 
10. Vinatier C, Mrugala D, Jorgensen C, Guicheux J, Noel D. Cartilage engineering: a crucial combination of cells, biomaterials and biofactors. Trends Biotechnol. 2009; 27(5):307-314. [PubMed: 19329205]

11. Pazzano D, Mercier KA, Moran JM, Fong SS, DiBiasio DD, Rulfs JX, Kohles SS, Bonassar LJ. Comparison of chondrogensis in static and perfused bioreactor culture. Biotechnol Prog. 2000; 16(5):893-6. [PubMed: 11027186]

12. Wu F, Dunkelman N, Peterson A, Davisson T, De La Torre R, Jain D. Bioreactor development for tissue-engineered cartilage. Ann NY Acad Sci. 1999; 875:405-411. [PubMed: 10415587]

13. Davisson TH, Sah RL, Ratcliffe AR. Perfusion increases cell content and matrix synthesis in chondrocyte three-dimensional cultures. Tissue Eng. 2000; 8:807-816. [PubMed: 12459059]

14. Sheehy EJ, Buckley CT, Kelly DJ. Chondrocytes and bone marrow-derived mesenchymal stem cells undergoing chondrogenesis in agarose hydrogels of solid and channelled architectures respond differentially to dynamic culture conditions. J Tissue Eng Regen Med. 2011 Epub ahead of print.

15. McGowan KB, Kurtis MS, Lottman LM, Watson D, Sah RL. Biochemical quantification of DNA in human articular and septal cartilage using PicoGreen and Hoechst 33258. Osteoarthritis Cartilage. Jul; 2002 10(7):580-587. [PubMed: 12127839]

16. Farndale RW, Buttle DJ, Barrett AJ. Improved quantitation and discrimination of sulphated glycosaminoglycans by use of dimethylmethylene blue. Biochim Biophys Acta. Sep; 1986 883(2): 173-177. [PubMed: 3091074]

17. Alexander TH, Sage AB, Schumacher BL, Sah RL, Watson D. Human serum for tissue engineering of human nasal septal cartilage. Otolaryngol Head Neck Surg. Sep; 2006 135(3):397403. [PubMed: 16949971]

18. Scott JE, Dorling J. Differential staining of acid glycosaminoglycans (mucopolysaccharides) by Alcian blue in salt solutions. Histochemistry and Cell Biology. 1965; 5(3):221-233.

19. Freed LE, Hollander AP, Martin I, Barry JR, Langer R, Vunjak-Novakovic G. Chondrogenesis in a cell-polymer-bioreactor system. Exp Cell Res. 1998; 240(1):58-65. [PubMed: 9570921]

20. Vunjak-Novakovic G, Martin I, Obradovic B, Treppo S, Grodzinsky AJ, Langer R, Freed LE. Bioreactor cultivation conditions modulate the composition and mechanical properties of tissueengineered cartilage. J Orthop Res. 1999; 17(1):130-138. [PubMed: 10073657]

21. Pound JC, Green DW, Chaudhuri JB, Mann S, Roach HI, Oreffo RO. Strategies to promote chondrogenesis and osteogenesis from human bone marrow cells and articular chondrocytes encapsulated in polysaccharide templates. Tissue Eng. 2006; 12(10):2789-2799. [PubMed: 17518648]

22. Gorti GK, Lo J, Falsafi S, Kosek J, Quan SY, Khuu DT, Koch J. Cartilage tissue engineering using cyrogenic chondrocytes. Arch Otolaryngol Head Neck Surg. 2003; 129:889-893. [PubMed: 12925350]

23. Rotter N, Aigner J, Naumann A. Behavior of tissue-engineered human cartilage after transplantation into nude mice. Journal of Materials Science: Materials in Medicine. 1999; 10:689-693. [PubMed: 15347987]

24. Bichara DA, Zhao X, Hwang NS, Bodugoz-Senturk H, Yaremchuk MJ, Randolph MA, Muratoglu OK. Porous poly(vinyl alcohol)-alginate gel hybrid construct for neocartilage formation using human nasoseptal cells. J Surg Res. 2010; 163(2):331-336. [PubMed: 20538292] 


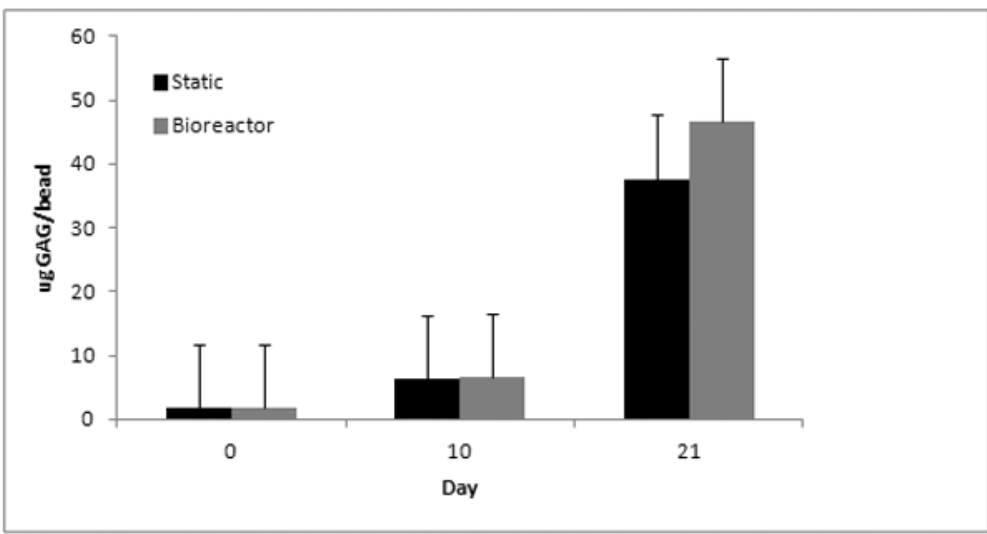

Figure 1.

Quantity of GAG per $\mu$ g DNA measured at day 0,10 , and 21 , in static and BR culture conditions. GAG accumulation did not vary between the culture conditions. However, there was a significant increase in GAG content from day 0 to 10 and 10 to 21 ( $p<0.001$ ). Error bars depict standard deviation. 

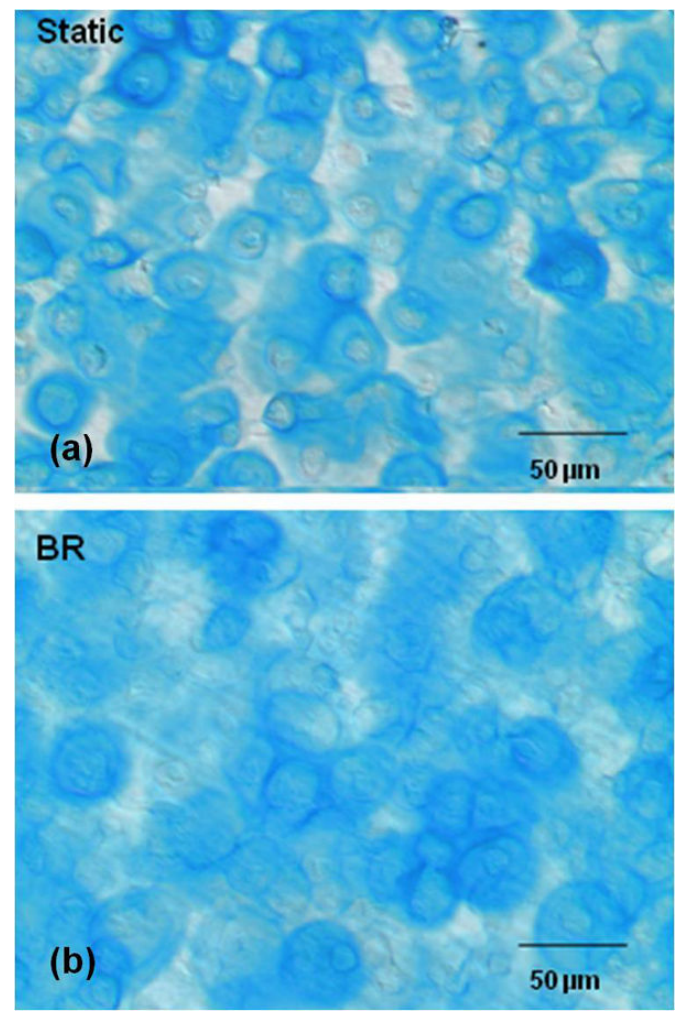

Figure 2.

Quantity of type II collagen per $\mu$ g DNA measured at day 0 and 21 in static and BR culture conditions. Type II collagen content did not vary between the culture conditions $(\mathrm{p}=0.639)$. 

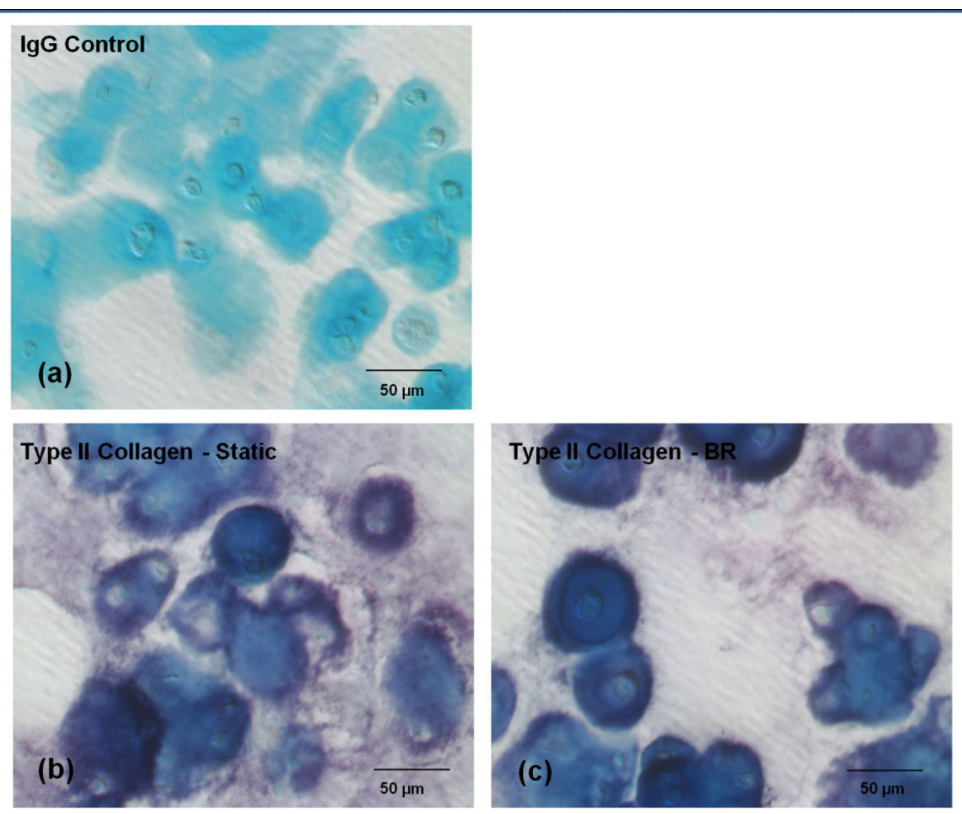

Figure 3.

Day 21 alginate beads exhibit robust staining with Alcian Blue, indicating abundant accumulation of GAG (40X magnification). 

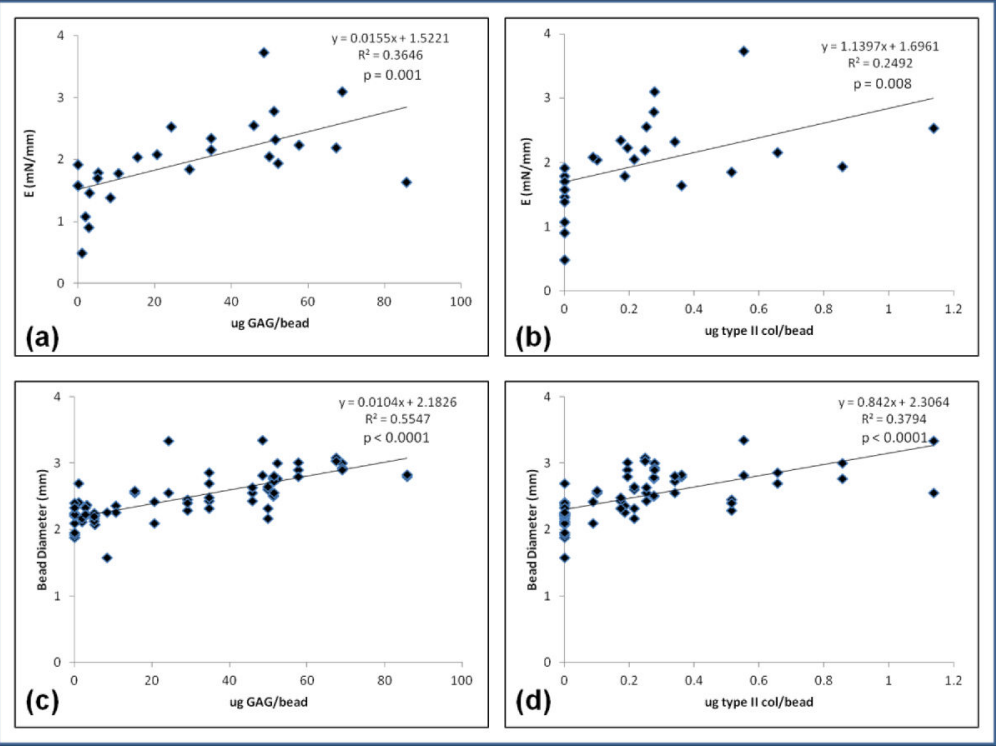

Figure 4.

IHC staining of day 21 alginate beads showed abundant type II collagen for both culture conditions with minimal staining for type I collagen and nonspecific IgG (pictures shown are representative of both culture conditions; 40X magnification). 